\title{
Acceptance Tendency of High-Level Taxis: From the Passengers' Perspective
}

\author{
Rong-Chang Jou and Ke-Hong Chen \\ Department of Civil Engineering, National Chi Nan International University, Nantou 54561, Taiwan \\ Correspondence should be addressed to Ke-Hong Chen; s3322904@ncnu.edu.tw
}

Received 1 May 2020; Revised 29 August 2020; Accepted 21 September 2020; Published 22 October 2020

Academic Editor: Michela Le Pira

Copyright (c) 2020 Rong-Chang Jou and Ke-Hong Chen. This is an open access article distributed under the Creative Commons Attribution License, which permits unrestricted use, distribution, and reproduction in any medium, provided the original work is properly cited.

In the present study, we used the stated preference approach to design different situations, including appearance, different services, and different times to further explore passengers' acceptance of and expected price to be paid for taxi service levels. In addition to using general ordered models, the results of this study were also compared with the multinomial logit model and the partial proportional odds (PPO) model. The results of comparison between the models ultimately revealed that the PPO model statistically had a better explanatory power. In the model estimation results, the key explanatory variables included the ability to recognize the appearance, seating space, honorable service, the development of user payment concepts, and demographic grouping, all of which could increase acceptance. The results obtained in this study could provide a key reference for the classification of taxis in the Taiwan region and serve as a basis for the development of strategies by operators in the future.

\section{Introduction}

Taxis are positioned as secondary mass transportation (paratransit) within urban transport. They are characterized by being quick, convenient, comfortable, and private motorized modes, door-to-door service, and are not subject to time limitations (e.g., departing late at night). In addition, passengers do not need to afford the cost of purchasing a vehicle, maintenance and repair costs, insurance, taxes, parking fees, and other expenditures. Research also indicates that taxis act as a part of public transportation, providing the public with convenient, point-to-point (the last mile) services.

However, taxis are not perfect modes of transportation. For example, single-trip fare is higher than that of mass transportation. At peak times, demand is greater than supply and it is difficult to hail a taxi. Additionally, a single rate for taxi cannot reflect the costs of different services, such as older or lack-of-maintenance taxi usually with uncomfortable air condition, unclean seat, and nosier ride quality. This makes customers feel that service quality is poor, which reduces riding rates. This also leads to a high percentage of empty taxis on the road and subsequently causes some negative effects, such as air pollution and $\mathrm{CO}_{2}$ emissions [1-4]. In addition, developments in new information technology have had a substantial impact on the taxi industry in recent years. For decades, the spread of personal mobile devices and applying this advantage to call a taxi through a mobile device has led to a rise in innovative services: for example, Uber [5] services more than 230 cities in 15 countries, Lyft's services [6] include 30 states in the United States, Hailo [7] serves 12 major cities in Europe, the United States, and several Asian regions, China's Didi Dache (Didi Dache) and Kuaidi Dache (Kuaidi Dache) have more than 1.5 million users (as discussed by Russell [8]), while Ola Cabs and TaxiForSure serve major cities in India [9]. The above services have quickly attracted consumers' interest through high service quality. However, their safety, legality, and other issues have also triggered a variety of disputes in different regions.

Taiwan's Ministry of Transportation and Communications has communicated the concepts of diversified taxis to the taxi industry since 2015: liberalizing the vehicle body colors of taxis, no longer limiting them to yellow; flexibly adding or removing roof lights depending on customer needs; adopting reservation systems for operations without 
cruising to find passengers or scheduling; the introduction of smart systems; and transparent operating information. When using an app to call a taxi, the app must provide the license plate number, the brand and model of the vehicle, the full name and a photograph of the driver, passenger ratings, estimated fare, vehicle's traveling trajectory, and other information. The above concepts can provide passengers with smarter, safer, and more convenient diverse transportation services.

Although the existing legislation regulated minimum requirements for taxi service quality (such as taxi drivers' qualification, vehicle exterior, etc.) by the National Police Agency and the Ministry of Transportation and Communications and, moreover, governments conducted annual taxi service evaluation in order to assist operators in establishing brands and undergoing evaluations to help operators actively increase their service quality, however, indepth investigations of the characteristics of users have not been conducted; the directions and feasible goals for improving service quality are not understood precisely. Therefore, the different feelings of users toward the relevant elements, such as taxi brand, vehicle age, displacement, and power types, all of which should increase passengers' acceptance of taxis, must be understood. In addition, experiences with urban taxi operations in other countries also indicate that a graded system can satisfy passengers with different needs, thereby increasing taxi service quality: for example, taxis in Seoul are divided into four different levels. Their external appearances also adopt lines of different colors. Taxis in Kuala Lumpur are divided into two types, general and luxury taxis. They are distinguished in their appearance by the colors red and blue, respectively. In Hong Kong, Shenzhen, and Tokyo, taxis are painted with different colors depending on their service areas. In all of the above regions, different appearances (colors, vehicle types), different service content (reservations, food and beverages within the vehicle, video entertainment, etc.), and different service hours (peak or off-peak) are adopted to serve as a basis for classification. The initial charges for these taxis range from US $\$ 0.71$ to US $\$ 1.50$ per kilometer. These charges jump by approximately US\$0.09 to US\$0.27 per kilometer. In particular, the charges for high-level service taxis in Kuala Lumpur and South Korea are nearly twice the charge for general taxis.

In summary, passengers were the subjects of the present study. The survey location was the taxi scheduling area at THSR (Taiwan High Speed Rail) Taichung Station. Passengers taking scheduled taxis were surveyed in the hope of exploring in depth the key factors influencing the acceptance of taxi service grades. The partial proportional odds (PPO) model, which has relatively strong explanatory power, was adopted in this study. The comprehensive estimation results from the model were used to provide recommendations for reference in the future development of taxi businesses in the Taiwan region. This study is based on passengers of taxis operating with charges based on taximeters. Operations with negotiated charges were not within the scope of this study. Additionally, with regard to taxi rates, rate structures and standards were not investigated.
The paper is organized as follows: Section 2 reviews the findings of the related literatures. Section 3 presents the model used in the study. Section 4 illustrates the experimental design and the data. Section 5 shows the results of the analysis carried out with each model and the comparison between them. And the final section summarizes our study's findings.

\section{Literature Reviews}

The majority of past studies on taxis explored the use of GPS positioning technology or new technological methods to improve the cruising of empty taxis, increase traveler convenience, enhance traveler satisfaction, and improve overall operating efficiency from the perspective of operators [10-12]. In addition, studies have also investigated behavior when driving to seek passengers [12] and the speeding violations of female professional drivers from the perspective of taxi drivers [13].

Shaaban and Kim [14] assessed taxi services in Doha, adopting structural equations for measurement in their research. The results of their study indicated that key items influencing taxi services include (1) socioeconomic background factors; (2) taxi call station status; (3) taxi business vehicle status; and (4) driver status.

A study by Hess and Bitterman [15] indicated that brand, marketing, and advertising can definitely influence people's travel behavior as well as their views toward public transportation, and the results illustrated that combining environmental awareness with leisure, entertainment, and brand building is a feasible direction. With regard to extended studies on the topic of environmental protection, Gao and Kitirattragarn [16] investigated the preferences of taxi operators in New York (including individual taxis and taxi fleets) for the purchase of hybrid electric vehicles (hybrid-electric vehicles, HEVs) as operating vehicles. They illustrated that if the future promotion of HEV in New York is supported by government policy, this could accelerate the realization of energy saving and carbon reduction. This study showed that vehicle models with different power methods for future taxis may in practice be a factor influencing passengers. In addition, new and innovative services have had an impact on the taxi industry. Although there may be concerns about statutory norms [17], app services to call taxis are widely accepted by users.

Although some studies have indicated that grading taxi services is a way to increase passenger satisfaction [18], a relatively small number of studies have analyzed this in depth from the passenger perspective. The present study explores this area.

The majority of studies that investigated ordinal scale in the past applied the following models: (1) the ordered logit model (OLM) [19-22]; (2) the generalized ordered response models [23]; (3) multinomial logit model (MNL) [24]; (4) mixed logit models [25-29]; and heteroskedastic models and latent class/finite mixture models have also been applied to different field studies to address the issue of unobserved heterogeneity [29-32]. 
In the application of these former models, several methodological issues were adopted for unobserved heterogeneity, omitted variable bias, with-in group correlation, and so on $[22,33-36]$.

The main focus of this study is the application of partial proportional odds (PPO) models for analyzing taxi service acceptance. The study also includes a comparison with two other fixed parameter models-ordered logit and multinomial logit (MNL) models.

Based on studies by Train [37] and Washington et al. [38], OLM can be derived based on latent variables that cannot be observed. The derivation process assumes that the data are consistent with the proportional odds assumption (partial proportional odds assumption). The so-called "proportional odds assumption" assumes that the coefficients of independent variables in two satisfaction levels are the same. The coefficients represent the slope; that is, the slope does not change on different levels [33]. In other words, individual heterogeneity cannot appear in OLM. In contrast, although the MNL model can maintain the heterogeneity of individual independent variables, its failing is that it overlooks the ordered characteristics of the acceptance levels. It makes statistical estimations using only categorical variables. Thus, both models are limited in their application. Relaxing the assumptions of the above two models, Williams [39] proposed the partial proportional odds model (PPO) to overcome the above issues. Sasidharan and Menéndez [36] used the three models, OLM, MNL, and PPO, to analyze the severity of injury of pedestrians in pedestrianvehicle accidents. Although the majority of the variables did not differ substantially between the three models, the likelihood ratio, AIC (Akaike's Information Criterion), and BIC (Bayesian Information Criterion) of the PPO model were the best of the three models. Additionally, the marginal benefit value of the PPO model was also the best of the three models. Therefore, in the present study, we adopted these three models, MNL, OLM, and PPO, to compare the differences in the acceptance of taxi grades among different user groups.

\section{Research Methods}

In the present study, we primarily investigated the acceptance of taxi service levels. Statistical models were used to estimate the coefficients and analyze the related significant factors and their effects, thereby providing specific references for the implementation of future transportation policies as well as a key basis for decision analysis. Among these models, the OLM and MNL models are already in wide use. Therefore, this study provides a more detailed introduction of only the PPO model.

According to the proportional odds assumption, the effect of an independent variable will be uniform for all levels of the dependent variable. However, in acceptance analysis, it is not logical to assume that the distances between different acceptance levels are the same.

Williams [39] expressed the probability $(P)$ of individual $(i)$ of the PPO model in each acceptance level $(j)$ as follows:

$$
P\left(Y_{i}>j\right)=P_{i j}=\frac{e^{\alpha_{j}+x_{1 i} \beta_{1}+x_{2 i} \beta_{2}+x_{3 i} \beta_{3 j}}}{1+e^{\alpha_{j}+x_{1 i} \beta_{1}+x_{2 i} \beta_{2}+x_{3 i} \beta_{3 j}}} .
$$

In this equation, $Y_{i}$ is defined as respondent $(i)$ acceptance scales of measurement; $\beta$ is the regression coefficient of $X$, whereas $\alpha_{j}$ is the intercept term of the acceptance level. Here, $x_{1}$ and $x_{2}$ satisfy the assumptions of the PPO model. Therefore, their corresponding coefficient values $\left(\beta_{1}\right.$ and $\left.\beta_{2}\right)$ are the same with values estimated on different acceptance levels. The corresponding coefficient value $\beta_{3}$ of $x_{3}$ maintains a changing state; that is, the coefficient values vary with different acceptance levels. This indicates that with different acceptance levels $(j)$ the $\beta$ coefficient value of the independent variable may be in a changing state. This means that individual independent variables influence different levels of acceptance response variables, expressing the impact of individual heterogeneity on the levels. However, some care is necessary with regard to interpreting the relevant variables in the model. The impact of positive or negative signs and different acceptance levels may retain different directionality [38].

In contrast, although the MNL model can maintain the heterogeneity of individual independent variables, its failing is that it overlooks the ordered characteristics of the satisfaction levels. It makes statistical estimations using only categorical variables. Therefore, the ordered logit and multinomial logit models are limited in their model applications.

With regard to the fit advantages and disadvantages of the different models, the AIC (Akaike's information criterion) and BIC (Bayesian Information Criterion) indicators can be used for judgment. This is because when the AIC and BIC indicators are used to measure statistical models, adding more predictors will increase likelihood values, often resulting in overfitting. Therefore, when estimating AIC and BIC, appropriate penalties are given to the predictors to prevent overfitting [40]. Equations (2) and (3) show the AIC and BIC calculations:

$$
\begin{aligned}
& \mathrm{AIC}=2 m-2 \ln \widehat{L}\left(M_{\text {full }}\right), \\
& \mathrm{BIC}=m \ln (N)-2 \ln \widehat{L}\left(M_{\text {full }}\right) .
\end{aligned}
$$

In these equations, $m$ is the estimated quantity of model parameters, $\widehat{L}\left(M_{\text {full }}\right)$ is the natural logarithmic likelihood including parameters, and $N$ is the number of observations. Lower AIC and BIC values indicate better model fit.

\section{Survey Design and Data Analyses}

4.1. Survey Design. Passengers were the subjects of the present study. The survey location was the taxi scheduling area at THSR (Taiwan High Speed Rail) Taichung Station with random sampling to gather our data. Passengers taking scheduled taxis were surveyed in the hope of exploring in depth the key factors influencing the acceptance of taxi service grades. This study is based on passengers of taxis operating with charges based on taximeters. Operations with negotiated charges were not within the scope of this study. Additionally, with regard to taxi rates, rate structures and standards were not investigated. 
The questionnaire (see Appendix 1) for this study was divided into two parts. The first part is a survey of the characteristics of taxi passenger travel behavior. The second part is a survey of personal socioeconomic backgrounds. These are detailed as follows.

4.1.1. Part I: Survey of the Characteristics of Taxi Passenger Travel. Main inquiries in the survey of the characteristics of taxi passenger travel are as follows: destination of this trip, total fare paid, whether the fare was subsidized, the main purpose of this trip, the time limit of this trip, the types of transportation used and the cost and time with the same starting and ending points in the past, main considerations when choosing to take a taxi, the monthly frequency of taxi use, acceptance of graded service strategies, preferences with regard to the features of highlevel service taxis to be provided in the future, charging systems and charge limits if extra payments are adopted in the future, differential characteristics in appearance for high-level service taxis, other innovative taxi-related services, acceptance of flexible charges in the future, and limits to flexible charging systems and acceptability in the future.

The item "preferences with regard to the features of high-level service taxis to be provided in the future" is further explained. This item references the investigative reports on taxi operations of the governments of Taipei City and Taichung City in the past and was amended. It contains a total of four dimensions (which includes hardware equipment dimension, Internet entertainment dimension, safety dimension, and brands dimension) with 16 characteristics; each characteristic was measured as a five-point Likert scale.

4.1.2. Part II: Survey of Personal Socioeconomic Backgrounds. Survey content included the following: (1) gender: male or female; (2) age: filled in by the respondents themselves; (3) education level: divided into four levels: high school (higher vocational education) and below, university or college, Master's, and doctorate; (4) marital status: married or unmarried; (5) place of residence: divided into Taichung City and other counties and cities.

\subsection{Data Analyses}

4.2.1. Travel Characteristics. Questionnaires were used to survey passengers taking scheduled taxis from THSR Taichung Station. A total of 200 questionnaires were collected. Table 1 shows the relevant analysis results for travel characteristics. The average taxi fare of the passengers was approximately USD $\$ 10.30$. Approximately 90\% of the passengers paid the entire fare themselves. The majority of passengers traveled one to two people (approximately 60\% of the total). In addition, these results also show that the majority of travelers taking taxis from the high speed rail station were on business trips (approximately 52\% of the total). The next most common purpose was returning home (approximately 28\% of the total). The average number of taxi trips per month was concentrated at four times or fewer (approximately 67\% of the total) which is consistent with prior knowledge. With regard to the time limitations of the current trip, as many as $81 \%$ of the passengers were not limited in their arrival times. This may be related to the high number of business trips, which are characterized by planned arrangements. In summary, the main considerations of passengers choosing to take taxis were primarily their convenient use, being pressed for time, their greater level of comfort in comparison to mass transportation, and the weather (accounting for 33\%, 18\%, 15\%, and $10 \%$, respectively).

Table 2 shows the analysis results on high-level service taxi acceptance. The results indicate that, among the passenger sample, high-level taxi acceptance was higher than non-acceptance (not including neutral), exceeding 50\%. This shows people's expectations and demands for high-level services. The related results from the present study can serve as an important reference for adjustments in administrative directions for related operating units or competent authorities.

Further analysis (Table 3) of each of the main dimensions reveals that if high-level service taxis are promoted in the future, (1) the passenger indicates that the provision of superior hardware services could increase high-level service taxi acceptance, but as many as $45 \%$ are neutral toward the service of high-displacement or hybrid vehicles. This shows that vehicle power is not a major concern for passengers. This may be because they are not driving and thus cannot perceive the differences. (2) In the dimension of Internet entertainment services, the provision of Internet connections and USB charging may have increased the passenger's willingness to accept high-level service taxis by a relatively substantial amount. This may have been because these services are already provided by existing highway coaches and some urban buses. (3) In the dimension of safety, all items were believed to be major contributors to increasing high-level service taxi acceptance. In addition, the passenger also rated driving record downloads as the number-two item increasing acceptance. (4) In the dimension of brands, the passenger held a neutral attitude toward operation by listed companies or wellknown cooperatives and service feedback.

4.2.2. Analysis of Personal Characteristics. Table 4 shows the analysis of the personal characteristics of the survey sample. The samples tended to be concentrated at the Bachelor's or Master's degree level, accounting for approximately $77 \%$ of the total. With regard to marital status, $56 \%$ of the samples were unmarried. With regard to monthly income analysis, the samples were concentrated at under USD\$1233.81, accounting for approximately $65 \%$ of the sample trend. The majority of the passengers were not residents of Taichung, accounting for approximately 56\%. The number of automobiles and scooters ownership by the passengers in Taichung was a larger $52 \%$ of surveyed travelers traveling with more 2 or more travelers. 
TABLE 1: Analysis of passengers' travel behavior characteristics.

\begin{tabular}{|c|c|c|}
\hline Item & Category & $\begin{array}{r}\text { Number of } \\
\text { samples (\%) }\end{array}$ \\
\hline \multirow{2}{*}{$\begin{array}{l}\text { Fare subsidies (average of USD } \$ 10.30 \text { (exchange rate: } \\
32.42 \text { NTD per USD (the exchange rate is based on the } \\
\text { quotation of Bank of Taiwan on } 31, \text { Dec, 2016)) ) }\end{array}$} & Fully self-paid & $179(89.5)$ \\
\hline & $\begin{array}{l}\text { Others (fully subsidized or } \\
\text { partially subsidized) }\end{array}$ & $21(10.6)$ \\
\hline \multirow{4}{*}{ Number of travelers (including the respondents themselves) } & 1 & $96(26.2)$ \\
\hline & 2 & $63(34.7)$ \\
\hline & 3 & $23(19)$ \\
\hline & 4 or more & $18(20.1)$ \\
\hline \multirow{3}{*}{ Purpose of trip } & Returning home & $58(28.6)$ \\
\hline & Business & $104(52.3)$ \\
\hline & Other & $38(19.0)$ \\
\hline \multirow{2}{*}{ Time limitations } & No & $163(81.4)$ \\
\hline & Yes (average of 32 minutes) & $37(18.6)$ \\
\hline \multirow{10}{*}{ Main considerations } & Convenient use & $133(33.2)$ \\
\hline & More comfortable than mass transportation & $60(15.0)$ \\
\hline & Reasonable prices & $17(4.2)$ \\
\hline & No mass transportation available & $20(5.0)$ \\
\hline & No private transportation available & $38(9.5)$ \\
\hline & Pressed for time & $74(18.5)$ \\
\hline & Entertainment equipment available for use & $4(1.0)$ \\
\hline & Weather considerations (such as rain) & $43(10.7)$ \\
\hline & Personal privacy & $6(1.5)$ \\
\hline & $\begin{array}{l}\text { Other reasons (picking up or seeing off coworkers or } \\
\text { friends, special engagements, cheaper when sharing } \\
\text { costs, etc.) }\end{array}$ & $6(1.5)$ \\
\hline \multirow{3}{*}{ Average trips per month } & 4 or fewer trips & $134(67.5)$ \\
\hline & $5-12$ trips & $45(22.8)$ \\
\hline & 13 or more trips & $19(9.6)$ \\
\hline
\end{tabular}

TABLE 2: Analysis of the characteristics of high-level taxi acceptance.

\begin{tabular}{|c|c|c|}
\hline Item & Choice & Samples (\%) \\
\hline \multirow{5}{*}{ High-level taxi acceptance } & Very difficult to accept & $6(0.9)$ \\
\hline & Not very acceptable & $43(13.4)$ \\
\hline & Neutral & $61(28.5)$ \\
\hline & Acceptable & $78(48.6)$ \\
\hline & Very acceptable & $11(8.6)$ \\
\hline \multirow{2}{*}{ High-level service charging approach } & Charging per time & $136(68.0)$ \\
\hline & Additional charge & $64(32.2)$ \\
\hline \multirow{6}{*}{ Appearance } & Limited vehicle models & $75(20.8)$ \\
\hline & Limited vehicle colors & $99(27.4)$ \\
\hline & Other identification or lights placed on the roof & $79(21.9)$ \\
\hline & Identification or lights placed on the windshield & $56(15.5)$ \\
\hline & Vehicle body pattern (text display) & $51(14.1)$ \\
\hline & Other (color of vehicle roof) & $1(0.3)$ \\
\hline
\end{tabular}

\section{Results of Model Estimation}

To understand the acceptance of high-level taxis among taxi passengers in depth, in addition to performing investigations using the PPO model, we also performed comparisons with the ordered logit model and the multinomial logit model. The model variables were the high-level taxi acceptance and characteristic items collected through the questionnaires. The variable "acceptance" was used as an dependent variable in modeling, and it was expressed as a five-point Likert scale. However, to increase the explanatory power of the models, acceptance was defined further in this study as three main parameters: unacceptable (combining very unacceptable and unacceptable), neutral, and acceptable (combining very acceptable and acceptable). The relevant model estimation results are further explored and interpreted as follows. In order to understand models' goodness of fit, we conducted McFadden pseudo $R$ square in the results.

Table 5 collects the results of the estimation using the ordered logit model. On the table, cut 1 refers to "from unacceptable to neutral" and cut 2 "from neutral to 
TABLE 3: Analysis of the characteristics of high-level taxi acceptance.

\begin{tabular}{|c|c|c|c|c|}
\hline Dimension & Item & Unwilling & Neutral & Willing \\
\hline \multirow{4}{*}{ Hardware equipment } & Imported top vehicle models (heated seats, air conditioning control) & $32(8.9)$ & $84(37.7)$ & $83(53.4)$ \\
\hline & New vehicles (within 5 years) & $8(4.0)$ & $62(31.2)$ & $87(43.7)$ \\
\hline & High-displacement or hybrid vehicles & $25(7.2)$ & $101(45.8)$ & $73(47.1)$ \\
\hline & Large seating space & $6(1.4)$ & $52(20)$ & $141(78.6)$ \\
\hline \multirow{2}{*}{ Internet entertainment } & Providing Internet connections and USB charging & $9(4.5)$ & $60(30.2)$ & $130(65.3)$ \\
\hline & Extra entertainment (beverages, music, etc.) & $49(24.6)$ & $85(42.7)$ & $65(32.7)$ \\
\hline \multirow{4}{*}{ Safety } & Driver grading (uniform clothing, multilingual, accident-free) & $3(1.5)$ & $61(30.7)$ & $135(67.8)$ \\
\hline & Driving record downloads & $4(2.0)$ & $61(30.7)$ & $134(67.3)$ \\
\hline & Physical separation between front and rear seats & $23(11.6)$ & $103(51.8)$ & $62(36.7)$ \\
\hline & Independent call for emergency assistance & $6(3.0)$ & $54(27.1)$ & $139(69.8)$ \\
\hline \multirow{6}{*}{ Brands } & Independent taxi hailing service (app, dedicated line) & $2(1.0)$ & $48(24.1)$ & $149(74.8)$ \\
\hline & Diverse methods of fare payment & $2(1.0)$ & $37(18.6)$ & $160(80.7)$ \\
\hline & Honorable service & $11(5.5)$ & $85(42.7)$ & $103(51.8)$ \\
\hline & Membership limited service & $37(18.6)$ & $86(43.2)$ & $61(38.2)$ \\
\hline & Operation by listed companies or well-known cooperatives & $8(4.0)$ & $98(49.3)$ & $93(46.8)$ \\
\hline & Service feedback (after trip) & $7(3.5)$ & $92(46.2)$ & $100(50.3)$ \\
\hline
\end{tabular}

TABle 4: Analysis of the socioeconomic backgrounds of the respondents.

\begin{tabular}{|c|c|c|}
\hline Item & Content & Samples (\%) \\
\hline \multirow{2}{*}{ Gender } & Male & $96(48.0)$ \\
\hline & Female & $104(52.0)$ \\
\hline \multirow{5}{*}{ Age } & Under 20 & $10(5)$ \\
\hline & $21-30$ & $64(32.2)$ \\
\hline & $31-40$ & $76(38.2)$ \\
\hline & $41-50$ & $37(18.6)$ \\
\hline & Over 51 & $14(7)$ \\
\hline \multirow{3}{*}{ Education level } & High school or lower & $34(17.1)$ \\
\hline & University or college & $125(62.5)$ \\
\hline & Master's or higher & $40(20.1)$ \\
\hline \multirow{2}{*}{ Marriage } & Married & $86(43.2)$ \\
\hline & Others & $113(56.5)$ \\
\hline \multirow{5}{*}{ Personal monthly income } & Below USD616.90 & $71(35.7)$ \\
\hline & USD616.90-below USD1233.81 & $59(29.6)$ \\
\hline & USD1233.81-below USD1850.71 & $20(9.9)$ \\
\hline & USD1850.71-under USD2467.61 & $21(11.0)$ \\
\hline & Over USD2467.61 & $26(13.0)$ \\
\hline \multirow{3}{*}{ Place of residence } & Former Taichung city & $52(26.1)$ \\
\hline & Former Taichung county & $35(17.6)$ \\
\hline & Other counties and cities & $112(56.3)$ \\
\hline \multirow{3}{*}{ Vehicle ownership-automobile } & 0 & $36(18.1)$ \\
\hline & 1 & $103(51.5)$ \\
\hline & More than 2 vehicles & $60(30.1)$ \\
\hline \multirow{3}{*}{ Vehicle ownership-scooter } & 0 & $26(13.1)$ \\
\hline & 1 & $107(53.5)$ \\
\hline & More than 2 vehicles & $66(33.1)$ \\
\hline
\end{tabular}

acceptable." Among the key explanatory variables, adopting limited vehicle colors for the main appearance of high-level service taxis was found to increase passengers' payment usage acceptance. This may be because limited vehicle colors facilitate identification on the road, reducing the likelihood that wrong choices will be made and improving the passenger experience. In addition, passengers who supported peak and off-peak differential rates may have done so because they were more accepting of the user payment concept. Therefore, they were similarly better able to accept the paid use of high-level service taxis. Residents of other counties and cities who were taking taxis in the Taichung region preferred paying to take high-level service taxis, perhaps to reduce the uncertainty of their journeys because they were unfamiliar with the geographical environment or the operating conditions of taxis at their destinations (such as the charging system). With regard to the characteristics of 
TABLE 5: Ordered logit model estimation results.

\begin{tabular}{lcc}
\hline Variable & Coef. & $t$-Value \\
\hline Vehicle body appearance-limited vehicle color & $0.63^{* *}$ & 2.10 \\
Approves of peak and off-peak differential rates & $0.55^{* *}$ & 3.24 \\
Place of residence-other counties and cities & $1.09^{* *}$ & 3.63 \\
Characteristic-large seating space & $2.75^{* *}$ & 2.29 \\
Characteristic-honorable service & $1.49^{* *}$ & 2.33 \\
Cut 1 & $5.60^{* *}$ & 3.76 \\
Cut 2 & $7.13^{* *}$ & 4.69 \\
LL $(0)$ & & -211.23 \\
LL $(\beta)$ & & -191.87 \\
Pseudo $R^{2}$ & & 0.09 \\
Samples & & 200 \\
\hline
\end{tabular}

** Significant at $95 \%$ confidence level; * significant at $90 \%$ confidence level.

high-level service taxis, preferences for large seating space and honorable service (such as the driver opening and closing the door, helping with luggage, and letting passengers control the air conditioning) could increase passengers' acceptance of payment for high-level service taxis. This illustrates that, in current taxi operations, passengers' willingness to pay more is low, perhaps because seating space varies, air conditioning cannot be controlled based on passengers' needs, or loading luggage is inconvenient. The key influencing variables of this study can serve as a reference on directions for improvement in the future.

Table 6 shows the multinomial logit model estimation results. Among the key explanatory variables, the key explanatory variables relative to the basic program (not accepting) for the passengers remained the same as those of the ordered logit model. Ability to identify appearance, seating space, and honorable service were all able to increase acceptance. In addition, passengers who approved of peak and off-peak differential rates were also found to be a significant variable. This illustrates that the development of user payment concepts is an indispensable factor that is critical to improving acceptance.

Table 7 shows the partial odd ratios model estimation results. In the model estimation, Panel II expresses intergroup comparisons: unacceptable against neutral + acceptable. Panel III expresses group comparisons: unacceptable + neutral against acceptable.

In the group investigation, the characteristic items (large seating space and honorable service) were set as explanatory variables of fixed effects. The results also show that passengers emphasized the feeling of space and courteous service during their trips. These two items are also areas where Taiwan's existing taxi services may be relatively unable to maintain steady service quality. We recommend that these areas be given priority for improvement when promoting the paid riding of high-level service taxis in the future.

In addition, the estimation results in group Panel II show that the explanatory directionality and explanatory variables in the overall model were consistent with those of the ordered logit model and the multinomial logit model. This indicates that, to make passengers willing to pay to use high-level service taxis, the ability to identify their exteriors, usage by passengers from other areas, and the development of users' payment concepts could all increase acceptance. Therefore, with regard to promotional strategies, unacceptable approaches should be given priority for improvement. With regard to areas that may require relatively active promotion in the near term, we recommend starting with improving recognition, stratification of the customer base, and developing additional payment concepts among users (such as additional fees for certain special services).

Additionally, the estimation results in group Panel III indicate that limiting the external colors of the vehicles does not improve acceptance. Therefore, with regard to promotional strategies, from the perspective of improving acceptance, that is, areas that will continue to increase attractiveness in the long term, we recommend that taxis maintain high-quality services while providing different customer bases with corresponding marketing strategies. At the same time, the user payment system should be adopted to increase market segmentation effects.

Finally, Table 8 shows the marginal benefit analysis of the partial odds ratio model. Based on the significant marginal effect coefficients, the acceptance rate of high-quality service taxis is higher among passengers who approve of the concept of peak and off-peak differential rates and reside outside of Taichung City and when taxi services with honorable service characteristics are provided. The appearance of the vehicle body (limited colors) can increase only the probability of neutral acceptance. With regard to the overall symbol trends, the marginal effect probability tended to increase numerically as acceptance increased. This indicates that the overall explanatory power and directionality of the model are correct.

We further estimated the AIC and BIC of the above three models: (1) the AIC of the ordered logit model, the multinomial logit model, and the partial odds ratio model were 22.5, 22.4, and 22.5, respectively. (2) The BIC of the ordered logit model, the multinomial logit model, and the partial odds ratio model were $1,189.4,1,189.5$, and $1,189.5$, respectively. The comparison results for the models indicate that the differences between AIC and BIC were not significant. However, the partial odds ratio model can provide 
Table 6: Multinomial logit model estimation results.

\begin{tabular}{|c|c|c|c|c|}
\hline \multirow{2}{*}{ Variable } & \multicolumn{2}{|c|}{ Acceptance-neutral } & \multicolumn{2}{|c|}{ Acceptance-satisfied } \\
\hline & Coef. & $t$-Value & Coef. & $t$-Value \\
\hline Constant term & -16.43 & -0.02 & $-7.39^{* *}$ & -4.02 \\
\hline Vehicle body appearance-limited vehicle color & $0.76^{*}$ & 1.77 & $0.97^{* *}$ & 2.26 \\
\hline Approves of peak and off-peak differential rates & 0.08 & 0.33 & $0.73^{* *}$ & 2.92 \\
\hline Place of residence-other counties and cities & 0.44 & 1.02 & $1.48^{* *}$ & 3.44 \\
\hline Characteristic-large seating space & 15.22 & 0.02 & $2.41^{*}$ & 1.94 \\
\hline Characteristic-honorable service & 0.76 & 0.94 & $2.07^{* *}$ & 2.23 \\
\hline LL $(0)$ & & & & \\
\hline $\operatorname{LL}(\beta)$ & & & & \\
\hline Pseudo $R^{2}$ & & & & \\
\hline Samples & & & & \\
\hline
\end{tabular}

${ }^{* *}$ Significant at $95 \%$ confidence level; ${ }^{*}$ significant at $90 \%$ confidence level.

TABLe 7: Partial odds ratio model estimation results.

\begin{tabular}{|c|c|c|c|c|}
\hline \multirow{2}{*}{ Variable } & \multicolumn{2}{|c|}{ Panel II } & \multicolumn{2}{|c|}{ Panel III } \\
\hline & Coef. & $t$-Value & Coef. & $t$-Value \\
\hline Constant term & $-5.14^{* *}$ & -3.29 & $-7.27^{* *}$ & -4.78 \\
\hline Vehicle body appearance-limited vehicle color & $0.88^{* *}$ & 2.32 & 0.49 & 1.48 \\
\hline Approves of peak and off-peak differential rates & $0.42^{*}$ & 1.91 & $0.63^{* *}$ & 3.15 \\
\hline Place of residence-other counties and cities & $0.98^{* *}$ & 2.58 & $1.13^{* *}$ & 3.23 \\
\hline Characteristic-large seating space & $2.73^{* *}$ & 2.28 & $2.73^{* *}$ & 2.28 \\
\hline Characteristic-honorable service & $1.41^{* *}$ & 2.20 & $1.41^{* *}$ & 2.20 \\
\hline LL $(0)$ & \multicolumn{4}{|c|}{-211.23} \\
\hline $\operatorname{LL}(\beta)$ & \multicolumn{4}{|c|}{-190.62} \\
\hline Pseudo $R^{2}$ & \multicolumn{4}{|c|}{0.10} \\
\hline Samples & \multicolumn{4}{|c|}{200} \\
\hline
\end{tabular}

${ }^{* *}$ Significant at $95 \%$ confidence level; ${ }^{*}$ significant at $90 \%$ confidence level.

TABLE 8: Marginal effects of partial odds ratio model.

\begin{tabular}{|c|c|c|c|c|c|c|}
\hline \multirow{2}{*}{ Variable } & \multicolumn{2}{|c|}{ Unacceptable } & \multicolumn{2}{|c|}{ Neutral } & \multicolumn{2}{|c|}{ Acceptable } \\
\hline & Coef. & $t$-Value & Coef. & $t$-Value & Coef. & $t$-Value \\
\hline Vehicle body appearance-limited vehicle color & $-0.14^{* *}$ & -2.8 & 0.04 & 0.67 & 0.10 & 1.43 \\
\hline Approves of peak and off-peak differential rates & $-0.07^{* *}$ & -2.33 & $-0.06^{*}$ & -1.50 & $0.13^{* *}$ & 3.25 \\
\hline Place of residence-other counties and cities & $-0.16^{* *}$ & -3.20 & $-0.08^{*}$ & -1.14 & $0.24^{* *}$ & 3.43 \\
\hline Characteristic-large seating space & $-0.55^{* *}$ & -2.89 & $0.16^{* *}$ & 2.29 & 0.39 & 1.50 \\
\hline Characteristic-honorable service & $-0.28^{* *}$ & -2.80 & 0.02 & 0.50 & $0.26^{* *}$ & 1.86 \\
\hline
\end{tabular}

${ }^{* *}$ Significant at $95 \%$ confidence level; ${ }^{*}$ significant at $90 \%$ confidence level.

more explanatory variables for reference during subsequent application.

Finally, public transportation development in Taichung was under proceeding; in order to access the final destination, passengers relied on the parent-transit (such as taxi or kiss-and-ride) to satisfy the demand. But it also conducted air pollution $\left(\mathrm{CO}_{2}\right.$ and other polluted elements increasing) and decreased the level of living environment.

\section{Conclusions and Recommendations}

Important conclusions and recommendations of this study are provided as follows:

(1) Analysis of each of the main dimensions indicates that, with regard to the future promotion of high-level service taxis, the majority of passengers are relatively willing to accept high-level service taxis. In the dimension of safety, driver grading is the main item that increased passengers' acceptance of high-level service taxis. In the dimension of brands, the passenger sample felt most neutral toward operation by listed companies or well-known cooperatives and service feedback. This may have been because the taxi operations in this project survey were already partially consistent with the expectations of the passenger sample. As a result, these two items were not major items increasing the acceptance of high-level taxis.

(2) In the model estimation results, the key explanatory variables included the ability to recognize the appearance, seating space, honorable service, the development of user payment concepts, and demographic grouping (passengers who reside in 
other counties and cities), all of which could increase acceptance. With regard to business strategies, in the near term, recommended areas that may require relatively energetic promotion include increasing recognition, stratification of the customer base, and developing additional payment concepts among users (such as additional fees for certain special services). In the long term, with regard to areas to continue to increase attractiveness, we recommend that taxis maintain high-quality services while providing different customer bases with corresponding marketing strategies and simultaneously adopting the user payment system to increase market segmentation effects.

(3) Although the innovation, in terms of methodology, is not that substantial, the study focuses on more realistic and practical aspects of investigating the acceptance behavior of high-level taxis from the passengers' point of views. Moreover, this study uses the partial proportional odds (PPO) model, a generalized more logit model compared to ordered logit (OL) model and multinomial logit (MNL) model, which relaxes the assumption that the coefficients of independent variables in different acceptance levels are the same.

(4) With regard to the model application results, the comparison results for the different models indicate that the fit, AIC, and BIC of each model were similar. However, the partial odds ratio (PPO) model was better able to provide more diverse explanatory content, capturing the impact factors and degrees of different grouping results.

(5) The scope of data collection in this study was taxi passengers at THSR (Taiwan High Speed Rail) Taichung Station, who were the main subjects. However, considering the differences in the regulated rates of the various local governments and competent authorities, we recommend extending the collection of samples to other regions in the future to gather and compare the relevant data, providing more objective findings on the special requirements of high-level taxi services.

(6) Both positive and negative impacts of taxis were addressed in the Introduction. The most serious issue caused by taxis is air pollution and $\mathrm{CO}_{2}$ emissions. Therefore, some incentives actions, e.g., incentives for BEV (battery electrical vehicle), can be promoted by the government to mitigate this problem.

\section{Appendix}

\section{A. Taxi Passengers' Acceptance Tendency towards High-Level Service Survey}

\section{A.1. Section 1: Taxi Passenger's Travel Behavior and Characteristics}

(1) About your riding experience this time, you take a taxi (the boarding location is Taichung Wuri Station)

\begin{tabular}{lcc}
\hline Mode & $\begin{array}{c}\text { Cost (NTD) } \\
\text { (including fare, } \\
\text { fuel charge, } \\
\text { parking fee) }\end{array}$ & $\begin{array}{c}\text { Travel time } \\
\text { (min) } \\
\text { (including } \\
\text { walking, access } \\
\text { time) }\end{array}$ \\
\hline $\begin{array}{l}\text { Bus (route No._, } \\
\text { Origin stop } \\
\text { Destination stop_ } \\
\text { Scooter } \\
\text { Automobile } \\
\text { Others }\end{array}$ \\
\hline
\end{tabular}

and get off at the district/city; road and intersection; The total fare is NTD ( $\square$ Fully-Self-Paid $\square$ Fully subsidized $\square$ Partially subsidized (NTD))

(2) Number of people traveling together (including yourself)?

(3) What is the purpose of the trip before taking the taxi? $\square$ Return home $\square$ Leisure travel $\square$ Business $\square$ Visit relatives or friends $\square$ Commute (work/study) $\square$ Seeking a doctor $\square$ shopping $\square$ Others

(4) Is there a time constraint for your arrival by taxi this time to your destination? $\square$ No $\square$ Yes, need to arrive within minutes

(5) Following Question \#1. On the same trip, which of the following vehicles have you ever used? (including transfer and waiting)

(6) What are the main reasons for choosing a taxi? (Check at most 3 items and fill in 1,2,3) $\square$ Easy to use (such as carrying a lot of luggage) $\square$ Comfortable (spacious seats, comfortable air-conditioning) $\square$ Reasonable price $\square$ No public transportation available $\square$ No other vehicle available $\square$ Urgency $\square$ Weather considerations (as raining) $\square$ Personal privacy $\square$ Others

(7) How often do you use it, on average, take a taxi about times a month.

(8) If taxi services are designed for grading, and highgrade taxis "provide more comprehensive and additional services and charge higher fees and are subject to government control." What is your acceptance of this strategy? $\square$ Very unacceptable $\square$ Unacceptable $\square$ Neutral $\square$ Acceptable $\square$ Very acceptable

(9) Please evaluate the following questions and check the corresponding results:

(10) If in the future high-grade taxis are used at an additional fee, in what way do you think the charging system should be more reasonable? $\square$ Charges per trip, additional___ yuan per trip is the upper limit of acceptable charges $\square$ According to the fare plus fee, additional $\%$ is the upper limit of acceptable charge

(11) In the future, when you pay for a service fee to use a high-grade taxi, what do you think should be 


\begin{tabular}{|c|c|c|c|c|c|c|}
\hline \multirow[b]{2}{*}{ Dimension } & \multirow[b]{2}{*}{ Item } & \multicolumn{5}{|c|}{ Degree of agreement } \\
\hline & & $\begin{array}{l}\text { Strongly } \\
\text { unwilling }\end{array}$ & Unwilling & Neutral & Willing & $\begin{array}{l}\text { Strongly } \\
\text { willing }\end{array}$ \\
\hline $\begin{array}{l}\text { Hardware } \\
\text { equipment }\end{array}$ & $\begin{array}{c}\text { Imported top vehicle models (heated seats, air } \\
\text { conditioning control) } \\
\text { New vehicles (within } 5 \text { years) } \\
\text { High-displacement or hybrid vehicles } \\
\text { Large seating space }\end{array}$ & & & & & \\
\hline $\begin{array}{l}\text { Internet } \\
\text { entertainment }\end{array}$ & $\begin{array}{l}\text { Providing Internet connections and USB charging } \\
\text { Extra entertainment (beverages, music, etc.) }\end{array}$ & & & & & \\
\hline Safety & $\begin{array}{c}\text { Driver grading (uniform clothing, multilingual, } \\
\text { accident-free) } \\
\text { Driving record downloads } \\
\text { Physical separation between front and rear seats } \\
\text { Independent call for emergency assistance }\end{array}$ & & & & & \\
\hline Brands & $\begin{array}{c}\text { Independent taxi hailing service (app, dedicated } \\
\text { line) } \\
\text { Diverse methods of fare payment } \\
\text { Honorable service } \\
\text { Membership limited service } \\
\text { Operation by listed companies or well-known } \\
\text { cooperatives } \\
\text { Service feedback (after trip) }\end{array}$ & & & & & \\
\hline
\end{tabular}

included in the service content? $\square$ Billing separately according to the service content $\square$ The service content package is charged once

(12) What kind of appearance do you think high-grade taxis should have? (check box, up to 3 items) $\square$ Limited car models $\square$ Limited car colors $\square$ Other signs or lights on the roof $\square$ Signs or lights on the front glass $\square$ The body painting is displayed with special patterns (text) $\square$ Others

(13) Have you ever used innovative transportationrelated services (such as Uber or Lyft)? $\square$ Never heard of $\square$ Heard, never used $\square$ Have used (when discounted or occasionally used) $\square$ Used often

(14) How do you accept flexible fares for booking taxi fares, such as higher demand during periods of high demand (such as peaks, rainy days, and time when activities are over), but ensure that there must be a car available for use? $\square$ Very unacceptable $\square$ Unacceptable $\square$ Neutral $\square$ Acceptable $\square$ Very acceptable

(15) Continuing from the previous question, in what way do you think the charging system should be more reasonable? $\square$ Charges per trip, additional yuan per trip is the upper limit of acceptable charges $\square$ According to the fare plus fee, additional _ $\%$ is the upper limit of acceptable charge

\section{A.2. Section 2: Personal Information}

(1) Gender: $\square$ Male $\square$ Female

(2) Age: __ years old
(3) Education Level: $\square$ below senior high school $\square$ Campus $\square$ Master $\square$ Ph. D.

(4) Marriage: $\square$ Married $\square$ Single

(5) Occupation: $\square$ Public opinion representatives, business executives and managers $\square$ Self-employed and commercial $\square$ Agriculture, forestry, fishery and animal husbandry workers $\square$ Military and public education personnel $\square$ Technical professionals $\square$ Business staff $\square$ Non-skilled and manual workers $\square$ Service staff Housekeeping $\square$ Student $\square$ Others

(6) Personal monthly income (NTD):

$\begin{array}{lr}\square \text { Below 25,000 } \square 25,001 \sim 35,000 & \square 35,001 \sim 45,000 \\ \square 45,001 \sim 55,000 \quad \square 55,001 \sim 65,000 & \square 65,001 \sim 75,000 \\ \square 75,001 \sim 85,000 \quad \square 85,001 \sim 90,000 & \square 90,001 \sim 95,000 \\ \square 100,001 \sim 105,000 & \square 105,001 \sim 110,000 \\ \square 110,001 \sim 115,000 & \square 115,001 \sim 120,000 \\ \square 120,001 \sim 125,000 & \square 125,001 \sim 130,000 \\ \square 130,001 \sim 135,000 & \square 135,001 \sim 140,000 \\ \square 140,001 \sim 145,000 & \square \text { Above 155,001 }\end{array}$

(7) Residence: $\square$ Taichung City $\square$ Other counties

(8) Vehicle ownership: Scooter ; Automobile

\section{Data Availability}

The data can be found in the Supplementary Information files.

\section{Conflicts of Interest}

The authors declare that they have no conflicts of interest. 


\section{Acknowledgments}

The authors thank the Ministry of Science and Technology in Taiwan for funding support during the research and preparation of the manuscript.

\section{Supplementary Materials}

Table 1: data for the manuscript. (Supplementary Materials)

\section{References}

[1] G. Inturri, S. Fiore, M. Ignaccolo, S. Caprì, and M. L. Pira, "You study, you travel free: when mobility management strategies meet social objectives," Transportation Research Procedia, vol. 45, pp. 193-200, 2020.

[2] K. Grondys, I. Kott, and K. Sukiennik, "Initiatives to reduce transport-related pollution in selected polish cities," Transportation Research Procedia, vol. 16, pp. 104-109, 2016.

[3] F. Cavallaro, R. Danielis, S. Nocera, and L. Rotaris, "Should BEVs be subsidized or taxed? A European perspective based on the economic value of $\mathrm{CO}_{2}$ emissions," Transportation Research Part D: Transport and Environment, vol. 64, pp. 70-89, 2018.

[4] Y. Liu, Y. Yuan, H. Guan, X. Sun, and C. Huang, "Technology and threshold: an empirical study of road passenger transport emissions," Research in Transportation Business \& Management, Article ID 100487, 2020.

[5] Uber, 2018, https://www.uber.com/cities.

[6] Lyft, 2018, https://www.lyft.com/cities.

[7] Hailo, 2016, https://en.wikipedia.org/wiki/Hailo.

[8] J. Russell, China's Top Two Taxi Apps Confirm That They Will Merge, vol. 13, TechCrunch, Bay Area, CA, USA, 2015, https:// techcrunch.com/2015/02/13/kuaididache-didi-dache-merge.

[9] A. Shrivastava, Olacabs Buys Competitor, Taxi for Sure, to Take on Competitors Like Uber; Deal Likely at INR 1250 Crore, vol. 29, Economic Times, Mumbai, India, 2015, http://articles. economictimes.indiatimes.com/2015-01-29/news/58586338_ 1_aprameya-radhakrishna-bhavish-aggarwal-taxiforsure.

[10] T. Miwa, Y. Ishiguro, T. Yamamoto, and T. Morikawa, "Allocation planning for probe taxi devices based on information reliability," Transportation Research Part C: Emerging Technologies, vol. 34, pp. 55-69, 2013.

[11] J. Jung, J. Y. J. Chow, R. Jayakrishnan, and J. Y. Park, "Stochastic dynamic itinerary interception refueling location problem with queue delay for electric taxi charging stations," Transportation Research Part C: Emerging Technologies, vol. 40, pp. 123-142, 2014.

[12] R. C. P. Wong, W. Y. Szeto, and S. C. Wong, "Bi-level decisions of vacant taxi drivers traveling towards taxi stands in customer-search: modeling methodology and policy implications," Transport Policy, vol. 33, pp. 73-81, 2014.

[13] M.-S. Yeh, C.-M. Tseng, H.-H. Liu, and L.-S. Tseng, "The factors of female taxi drivers' speeding offenses in Taiwan," Transportation Research Part F: Traffic Psychology and Behaviour, vol. 32, pp. 35-45, 2015.

[14] K. Shaaban and I. Kim, "Assessment of the taxi service in Doha," Transportation Research Part A: Policy and Practice, vol. 88, pp. 223-235, 2016.

[15] D. B. Hess and A. Bitterman, "Branding and selling public transit in North America: an analysis of recent messages and methods," Research in Transportation Business \& Management, vol. 18, pp. 49-56, 2016.
[16] H. O. Gao and V. Kitirattragarn, “Taxi owners' buying preferences of hybrid-electric vehicles and their implications for emissions in New York City," Transportation Research Part A: Policy and Practice, vol. 42, no. 8, pp. 1064-1073, 2008.

[17] S. E. Harding, M. G. Badami, C. C. O. Reynolds, and M. Kandlikar, "Auto-rickshaws in Indian cities: public perceptions and operational realities," Transport Policy, vol. 52, pp. 143-152, 2016.

[18] Institute of transportation and Ministry of Transportation and Communications, Rationalization of Classifications and Fare Structure of Taxicab in Taiwan, Government Publications, Taiwan, China, 2001.

[19] S. Yasmin, N. Eluru, and S. Ukkusuri, "Examining driver injury severity in two vehicle crashes-a copula based approach," In: Technical Paper, Department of Civil Engineering and Applied Mechanics, McGill University, Montreal, Canada, 2013.

[20] S. Yasmin, N. Eluru, and S. Ukkusuri, "Alternative ordered response frameworks for examining pedestrian injury severity in New York City," Journal of Transportation Safety and Security, vol. 6, no. 4, pp. 275-300, 2013.

[21] N. Eluru, "Evaluating alternate discrete choice frameworks for modeling ordinal discrete variables," Accident Analysis \& Prevention, vol. 55, pp. 1-11, 2013.

[22] S. Yasmin and N. Eluru, "Evaluating alternate discrete outcome frameworks for modeling crash injury severity," Accident Analysis \& Prevention, vol. 59, pp. 506-521, 2013.

[23] C. O'Donnell and D. Connor, "Predicting the severity of motor vehicle accident injuries using models of ordered multiple choices," Accident Analysis and Prevention, vol. 28, no. 6, pp. 739-753, 1996.

[24] G. F. Ulfarsson and F. L. Mannering, "Differences in male and female injury severities in sport-utility vehicle, minivan, pickup and passenger car accidents," Accident Analysis \& Prevention, vol. 36, no. 2, pp. 135-147, 2004.

[25] N. Eluru, C. R. Bhat, and D. A. Hensher, "A mixed generalized ordered response model for examining pedestrian and bicyclist injury severity level in traffic crashes," Accident Analysis \& Prevention, vol. 40, no. 3, pp. 1033-1054, 2008.

[26] J.-K. Kim, G. F. Ulfarsson, V. N. Shankar, and S. Kim, “Age and pedestrian injury severity in motor-vehicle crashes: a heteroskedastic logit analysis," Accident Analysis \& Prevention, vol. 40, no. 5, pp. 1695-1702, 2008.

[27] J. K. Kim, G. Ulfarsson, V. Shankar, and F. Mannering, “A note on modeling pedestrian injury severity in motor vehicle crashes with the mixed logit model," Accident Analysis and Prevention, vol. 42, no. 6, pp. 1073-1081, 2010.

[28] J. Mooradian, J. N. Ivan, N. Ravishanker, and S. Hu, "Analysis of driver and passenger crash injury severity using partial proportional odds models," Accident Analysis \& Prevention, vol. 58, pp. 53-58, 2013.

[29] C. R. Bhat, K. Born, R. Sidharthan, and P. C. Bhat, "A count data model with endogenous covariates: formulation and application to roadway crash frequency at intersections," Analytic Methods in Accident Research, vol. 1, pp. 53-71, 2014.

[30] B.-J. Park and D. Lord, "Application of finite mixture models for vehicle crash data analysis," Accident Analysis \& Prevention, vol. 41, no. 4, pp. 683-691, 2009.

[31] B.-J. Park, D. Lord, and J. D. Hart, "Bias properties of Bayesian statistics in finite mixture of negative binomial regression models in crash data analysis," Accident Analysis \& Prevention, vol. 42, no. 2, pp. 741-749, 2010.

[32] Y. Zou, Y. Zhang, and D. Lord, "Application of finite mixture of negative binomial regression models with varying weight 
parameters for vehicle crash data analysis," Accident Analysis \& Prevention, vol. 50, pp. 1042-1051, 2013.

[33] X. Wang and M. Abdel-Aty, "Analysis of left-turn crash injury severity by conflicting pattern using partial proportional odds models," Accident Analysis \& Prevention, vol. 40, no. 5, pp. 1674-1682, 2008.

[34] F. Ye and D. Lord, "Investigation of effects of underreporting crash data on three commonly used traffic crash severity models," Transportation Research Record: Journal of the Transportation Research Board, vol. 2241, no. 1, pp. 51-58, 2011.

[35] L. Sasidharan and E. T. Donnell, "Application of propensity scores and potential outcomes to estimate effectiveness of traffic safety countermeasures: exploratory analysis using intersection lighting data," Accident Analysis \& Prevention, vol. 50, pp. 539-553, 2013.

[36] L. Sasidharan and M. Menéndez, "Partial proportional odds model-An alternate choice for analyzing pedestrian crash injury severities," Accident Analysis \& Prevention, vol. 72, pp. 330-340, 2014.

[37] K. Train, Discrete Choice Methods with Simulation, Cambridge University Press, Cambridge, UK, 2nd edition, 2009.

[38] S. P. Washington, M. Larlaftis, and F. L. Mannering, Statistical and Econometric Methods for Transportation Data Analysis, Chapman \& Hall/CRC, Boca Raton, FL, USA, 2011.

[39] R. Williams, "Generalized ordered logit/partial proportional odds models for ordinal dependent variables," The Stata Journal: Promoting Communications on Statistics and Stata, vol. 6, no. 1, pp. 58-82, 2006.

[40] D. Posada and T. R. Buckley, "Model selection and model averaging in phylogenetics: advantages of akaike information criterion and bayesian approaches over likelihood ratio tests," Systematic Biology, vol. 53, no. 5, pp. 793-808, 2004. 